\title{
Improving the resilience of existing built assets to earthquake induced liquefaction disaster events
}

\author{
Keith G. Jones ${ }^{1}$ (D) - Mariantonietta Morga ${ }^{1}$ (D) . Nadeeshani Wanigarathna' \\ Federica Pascale $^{1}$ D $\cdot$ Abdelghani Meslem $^{2} \mathbb{D}$
}

Received: 23 April 2020 / Accepted: 8 October 2020 / Published online: 27 January 2021

(c) The Author(s) 2021

\begin{abstract}
LIQUEFACT was a EU H2020 funded project to investigate earthquake induced liquefaction potential across Europe and develop a series of tools to understand better the impacts that earthquake induced liquefaction disaster events have on the resilience of built assets and communities. A resilience assessment and improvement framework was developed to provide the theoretical underpinning for the LIQUEFACT project and to provide practical guidance on the assessment of built assets to Earthquake Induced Liquefaction Disaster events through the LIQUEFACT software tool and built asset management planning framework. This paper outlines the theoretical basis to the resilience assessment and improvement framework and built asset management planning framework and presents the results from a validation exercise through their application to a hypothetical healthcare scenario. The paper also describes the different stages of the research that led to the definition of the resilience assessment and improvement framework and built asset management planning framework. To this end the paper concludes that the resilience assessment and improvement framework and built asset management framework provide a longitudinal, holistic view of disaster vulnerability and resilience that can inform the selection of ground improvement mitigation actions to improve business continuity and resilience planning.
\end{abstract}

Keywords Built asset management - Mitigation - Earthquake induced liquefaction · resilience $\cdot$ Disaster management

Keith G. Jones

keith.jones@anglia.ac.uk

Mariantonietta Morga

mariantonietta.morga@anglia.ac.uk

Nadeeshani Wanigarathna

nadeeshani.wanigarathna@anglia.ac.uk

Federica Pascale

federica.pascale@anglia.ac.uk

Abdelghani Meslem

abdelghani.meslem@norsar.no

Anglia Ruskin University, Chelmsford, UK

2 NORSAR, Kjeller, Norway 


\section{Introduction}

The UNDRR define resilience as "the ability of a system, community or society exposed to hazards to resist, absorb, accommodate, adapt to, transform and recover from the effects of a hazard in a timely and efficient manner, including through the preservation and restoration of its essential basic structures and functions through risk management." (UNDRR 2017).

Improved resilience to disaster events relies on the complex interaction between community stakeholder groups (Boon et al. 2012; Cavallo 2014; Cutter et al. 2008; Hallett 2013; Paton et al. 2013; Paton and Johnston 2017; Tierney and Bruneau 2007), and in particular on the effects that the reduced functional performance of one stakeholder group has on the functional performance of the others (Ali and Jones 2013; Gibson and Tarrant 2010; Johnston et al. 2017). Within this complex system, the built environment, including the critical infrastructure that supports modern living, are key systems that if not effectively managed (Prior 2015) can have a major impact on the ability of a community to prepare for, absorb and recover from, a disaster event (Mieler et al. 2015; Wang et al. 2018).

Understanding the complex interactions between built environment systems and community resilience requires an integrated approach to assessing not only the impact that a disaster event has on the physical vulnerability of built assets, but also on the critical infrastructure organisation's ability to deliver its core product or service (Achour et al. 2011; Gibson and Tarrant 2010; Johnston et al. 2017). However, whilst methods and practices for identifying the effects of disaster events on the physical integrity of built assets are well established (FEMA 2006) methods for assessing the impact that different damage levels (states) have on the functionality of built asset (FEMA 2012; Filiatrault and Sullivan 2014; Masi et al. 2013; UNDRR 2020) or on an organisation's risk assessments and disaster management/business continuity plans (Warren 2010) are less well developed.

Whilst many authors have reported studies and developed models linking community factors to resilience (Ainuddin and Routray 2012; Becker et al. 2013; Cimellaro 2016; Cutter et al. 2010; Paton and Johnston 2017; Tiernan et al. 2019; Tierney and Bruneau 2007) far fewer have developed practical toolkits to help policy makers understand city vulnerabilities and identify mitigation interventions that could reduce these vulnerabilities and improve city resilience to future disaster events (The Rockefeller Foundation 2015; UNISDR 2017). Those toolkits that have been developed have tended to be either formative, where the focus is on understanding the processes that contribute to resilience, or summative where the focus is out-come based (Sharifi 2016). Toolkits tend to use scorecards where workshops with different end-user stakeholders identify hazard impacts/risks and mitigation intervention action plans (Johnston et al. 2017; Sharifi 2016; UNDRR 2020). These interventions can be evaluated through a built asset options appraisal approach and the most beneficial integrated into the built asset lifecycle (Hallett 2013; Jones et al. 2013). The LIQUEFACT project has developed a resilience assessment and improvement framework (RAIF) and Built Asset Management (BAM) planning tool for integrating built asset level Earthquake Induced Liquefaction Disaster (EILD) mitigation interventions into the built asset life cycle. In developing the RAIF and BAM planning tool the LIQUEFACT project extended the scope of BAM beyond a narrow consideration of current service level performance to a wider consideration of the impact that an EILD event would have on the ability of the built asset to continue to deliver its primary function (production or service delivery) following a disaster event (Morga et al. 2020). This paper presents an overview of the theories that underpin the RAIF and discusses the iterative research process through 
which they were integrated into the RAIF and BAM planning framework. The paper also describes the validation of the RAIF and BAM planning framework through its application to a hypothetical healthcare scenario.

\section{Background to the LIQUEFACT project}

Recent events (Italy, Japan, New Zealand) have demonstrated that EILD events are responsible for significant structural damage and economic losses (Fioravante et al. 2013; Cubrinovski et al. 2014; van Ballegooy et al. 2014; Wood et al. 2016).

Several kind of phenomena are defined as earthquake induced soil liquefaction in the scientific and technical literature (Kramer 2014). All of them are characterized by soil deformations due to monotonic, transient or cyclic excitation occurring in saturated cohesionless soil under undrained conditions. The undrained conditions produce a densification of the solid particles and an increase of the interstitial pressure and a consequent reduction of the effective stresses. The reduction of the effective stresses causes a reduction of the bearing capacity of the foundation soil (Kramer 2014). The excess pore pressure decreases when the liquefiable layer breaks through the impermeable soil layers resulting in a drained condition (Kramer 2014) and often visible phenomena such as sand ejecta on the ground surface.

Whilst the causes of liquefaction (Kramer 2014) and their impact of the physical performance of built assets (Cubrinovski et al. 2014) have been investigated in many studies (Bhattacharya and Bolton 2004; Zheng and Luna 2006; Bird et al. 2006; Bray and Dashti 2014; Bray and Macedo 2017), their impact (along with other seismic impacts) on the functional performance of built assets have been less well studied. Where assessments of the impact of seismic activity on functional performance do exist, they tend to focus on loss calculations (FEMA 2012; Perrone et al. 2019) of nonstructural components generated for insurance purposes, with very few addressing the impact that reduced functionality has on organisational performance and service delivery (Achour 2011; Cimellaro et al. 2010). To the best of the authors' knowledge no previous studies explicitly investigate the link between the functional performance of built assets and the impacts of EILD events; or on integrating mitigation to EILD events into business continuity and resilience plans. As such, built asset owners and managers currently lack the detailed tools to assess the impact that any vulnerabilities have on their organisation's ability to deliver its primary function during, and immediately after an EILD event. The RAIF and BAM developed in the LIQUEFACT project address these issues.

\section{Review of literature and theory}

Vulnerability, resilience and coping capacity are concepts used to study the complex relationships between communities and the built environment (Cimellaro 2016; Gallopín 2006; Holling 1996; Matyas and Pelling 2012; Tiernan et al. 2019). In applying these concepts researchers have been wary of the influence that the different philosophical perspectives of resilience (Holling 1973, 1996) have on the inter-relationships between vulnerability, resilience and coping capacity. Whilst at the individual built asset level engineering resilience (which considers the stability of a system near its equilibrium point) helps frame the impact that a disaster event has on the functional performance of built assets (Bruneau 
et al. 2003; Manyena 2006) and its potential to 'bounce back' following a disaster event (Tiernan et al. 2019) it doesn't consider the dynamic social nature of communities (Cutter et al. 2010). Socio-ecological resilience on the other hand considers resilience to be a complex adaptive system where feedback and self-organisation allow the system to reconfigure to a different equilibrium state (Boon et al. 2012; Cavallo 2014; Hallett 2013; Holling 2001). In such systems adaptive capacities (e.g. social, economic) and policy interventions (community and business) help build and enhance a communities response to, and recovery from disaster events (Cutter et al. 2010; Pescaroli and Alexander 2016; Prior and Hagmann 2012; Tiernan et al. 2019). The importance of adopting a system approach to modelling resilience to disaster events was also noted by Melkunaite (2016) and Ostadtaghizadeh et al. (2015) who identified system context and function as key contributors to adaptation and bounce-back and suggested the need for different perspectives of resilience to be used to reflect different system components and link built asset resilience to community resilience (Mieler et al. 2015; Prior and Hagmann 2012; Wang et al. 2018). The RAIF combined both engineering and socio-ecological resilience concepts to link hazard risk, to system performance and community resilience.

\subsection{Disaster resilience of place}

Many authors have developed models and toolkits to assess the resilience of communities and built assets to disaster events (Becker et al. 2013; Cimellaro 2016; Cutter et al. 2008, 2010; Matyas and Pelling 2012; Paton 2007; Paton et al. 2013; Paton and Johnston 2017; Tiernan et al. 2019; Tierney and Bruneau 2007) and whilst there is general agreement of the factors that affect community resilience, there is less agreement on how to integrate these into practical toolkits (Sharifi 2016). Those toolkits that have been developed (Cutter et al. 2010; Prior 2015; Johnston et al. 2017; Wang et al. 2018; UNDRR 2020) tend to start by defining the system (domains, components, characteristic, factors) and hazard threat (event characteristics) being modelled and developing metrics that describe how the system would respond to the hazard threat. The metrics can then be combined to provide a measure of the system's resilience (Morga et al. 2020). Mitigation options for improving resilience are evaluated by considering how each mitigation intervention changes the metric scores. The resilience scores from each system can be linked to overall community resilience by ensuring community goals are reflected in built environment performance targets (Mieler et al. 2015; Wang et al. 2018). This basic approach was applied to the development of the RAIF; with the Disaster Resilience of Place (DROP) model (Cutter et al. 2008) providing the theoretical basis linking vulnerability to resilience and built environment performance to community resilience (Fig. 1).

The DROP model (Cutter et al. 2008) links the existing vulnerability and resilience of a 'place' (antecedent conditions) to the impact that a disaster event (described by the event characteristics and coping responses) has on the ability of a community (absorptive capacity) to recover from the event (Jones 2012). If following an event those responsible for the system/community integrate mitigation and preparedness into their disaster management and resilience planning then the antecedent conditions are improved before the next occurrence of a similar disaster event.

The DROP model has previously been identified (Davis 2017; Lundgren and Jonsson 2012; Mieler et al. 2015; Prior and Hagmann 2012) as a suitable framework to model the longitudinal relationship between the impact of a disaster event on a place (Matyas and Pelling 2012; Tiernen et al. 2019). Further, the explicit connection of vulnerability to 


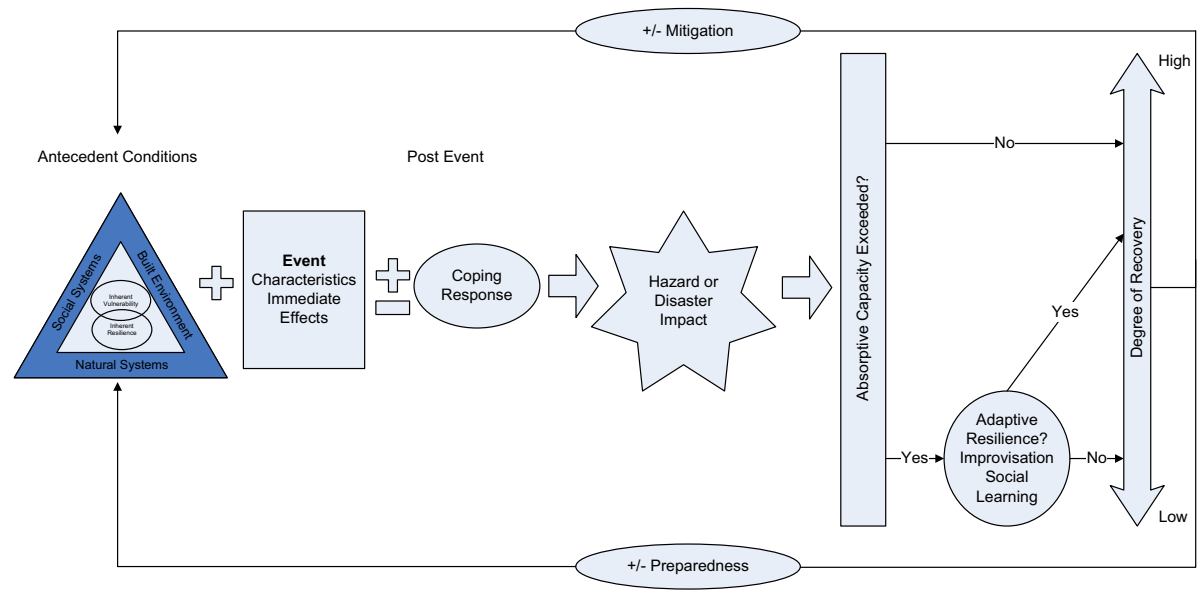

Fig. 1 Schematic representation of the disaster resilience of place (DROP) model. Source: Cutter et al. (2008)

resilience in a longitudinal manner reflects both their dynamic nature and accommodates preparedness and mitigation action, which are critical to effective decision making (Prior and Hagmann 2012). Thus, whilst the DROP model does not include the more subjective aspects of resilience, and is difficult to articulate at the macro and mezzo scales (Prior and Hagmann 2012), it does provide a practical approach for stakeholders to frame vulnerability and benchmark community resilience (Tiernen et al. 2019). This was demonstrated by the CREW project (Hallett 2013) where the DROP model was mapped against the built asset lifecycle to accommodate the integration of mitigation interventions into BAM business models. The LIQUEFACT project built on the approach used in the CREW project.

\subsection{Built asset management}

Built Asset Management is a strategic activity designed to ensure that built assets perform in a way that ensures effective delivery of an organisation's core product or service) over the built asset's lifecycle (Alwan and Gledson 2015; Finch 1998; Jones 2002; Pukītea and Geipeleb 2017). In essence BAM seeks to map the performance of an organisation's built assets to its critical success factors and understand the root cause of any performance gaps (obsolescence). If performance gaps exist then solutions in the form of pro-active physical or operational mitigation actions are developed (Smyth et al. 2017; Too and Too 2010) and those that offer the greatest potential (measured through an options appraisal process) to reduce existing or potential future obsolescence are adopted (Fig. 2).

In the context of disaster management BAM involves understanding the impact that a disaster event would have on an organisations built assets and on how this impact would affect the organisation's ability to deliver its core product or service (Jones et al. 2017). At some point in the normal built asset life-cycle a disaster event will cause a sudden and significant drop in the functional performance of the built asset. This drop will be a combination of the effect of the impact of the disaster event on the physical, economic, social and environmental attributes of the built asset and will be manifest through the reduced ability of the built asset to deliver against its primary function (e.g. production or service delivery). The severity of the loss of performance can be reduced by retrofitting, before a 


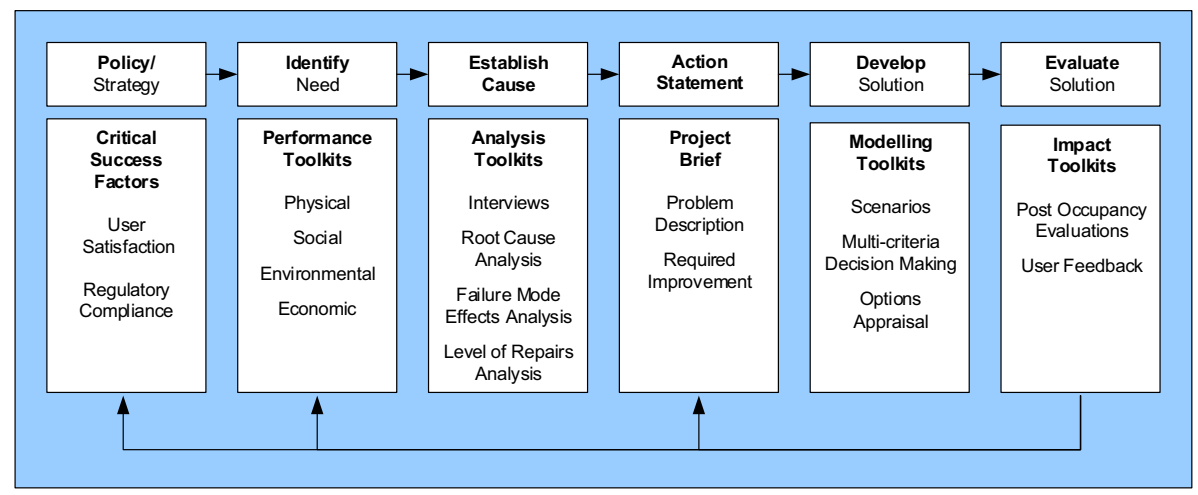

Fig. 2 Performance based built asset management process model (adapted from Jones and Sharp 2007)

disaster event occurs, technical mitigation measures to reduce the built assets vulnerability and/or improve its resilience. Further, the recovery trajectory following a disaster event can be accelerated through the inclusion of managerial (both strategic and operational policies) and organisational (attitude to risk and insurance) mitigation actions in disaster management/business continuity plans.

The LIQUEFACT project used the performance based built asset management process model (Jones and Sharp 2007) as the basis of a resilience assessment and improvement framework to identify the range of tools (Fig. 2) needed to justify the pre-emptive inclusion of EILD mitigation interventions into BAM plans. The application of the performance based model built on exiting research (Hallett 2013) that used a similar approach to evaluate the vulnerability and resilience of a major UK social housing provider's building stock to extreme weather events (Hallett 2013) and develop a built asset management planning tool to integrate built asset mitigation interventions for flooding into long-term built asset management plans (Jones et al. 2017). The LIQUEFACT project extended this work to the development of the RAIF and BAM planning framework for integrating built asset level EILD mitigation interventions into the built asset life cycle.

\section{Research methods}

The aim of the RAIF was to provide an integrating framework linking technical solutions (developed across the LIQUEFACT project) with business (BAM) and community models (Jones et al. 2020). An iterative, action research based methodology, combining both quantitative and quantitative approaches was used to develop an holistic understanding of the impact that EILD mitigation interventions could have on built asset and community resilience (Fig. 3). A quantitative approach was used to assess the potential of the UNDRR Disaster Resilience Scorecard for Cities to provide the basis for assessing the impact built asset mitigation interventions to an EILD event have on community resilience (reported in Jones et al. 2020). A qualitative approach was used to develop the RAIF and to provide the theoretical underpinning for the integration of tools developed across the LIQUEFACT project in a BAM planning framework. A narrative literature review was undertaken to identify the theoretical models and operational toolkits of community vulnerability and resilience. The literature review also examined the 


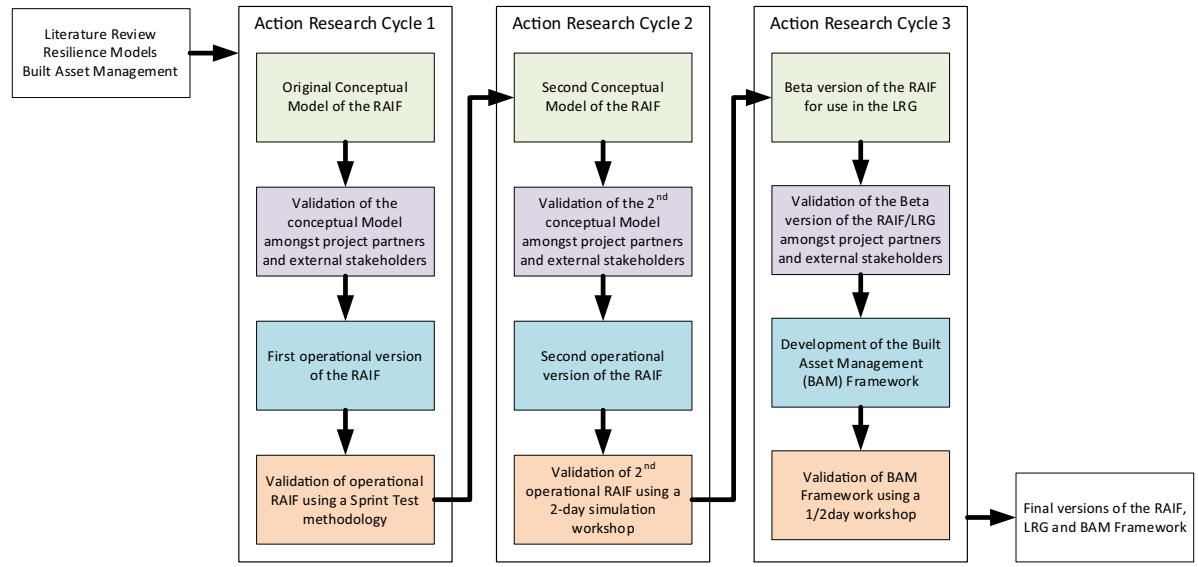

Fig. 3 Research framework

theoretical basis for built asset management planning to support the integration of EILD mitigation interventions into the built asset lifecycle. The literature review led to the development of a conceptual RAIF model (version 1).

The conceptual RAIF model was further developed through 2 workshops in Bologna and Ferrara and a series of technical meetings with LIQUEFACT project partners and an International Expert Advisory Group (IEAG). The Bologna workshop (205 participants) presented the RAIF to an expert stakeholder group with recent knowledge of EILD events from the Emilia Romagna Region of Italy (3rd October 2016). The Ferrara workshop (4th and 5th October 2016) explored the practical requirements of the technical tools needed to operationalise the RAIF. The RAIF and initial research tool specifications were reviewed at an IEAG meeting on 5th October 2017 in Naples.

A one-day workshop was held in Rome on the 17th November 2017 to test the RAIF and initial research tools against a hypothetical healthcare scenario. This workshop was attended by the LIQUEFACT partners. A simplified healthcare scenario comprising 4 buildings located on a single site in a small city was used to test each stage of the RAIF. It was assumed that the buildings had been designed to resist ground shaking but not earthquake induced liquefaction. Version 2 of the RAIF was developed following the workshop.

Four further review workshops were held in Porto (2-4th May 2018); Oslo (1st-5th October 2018); Istanbul (2-6th April 2019) and Pavia (8-12th October 2019) and a further IEAG workshop was held in Oslo (5th October 2018). At these workshops each research team presented their research tools and demonstrated how they fitted the requirements of the RAIF and LIQUEFACT software. Detailed feedback on both the engineering science and practical usefulness of each tool was given to each research team to support the further development of their tools.

Finally, a two-day validation workshop was held between researchers developing the RAIF and BAM planning framework and the LIQUEFACT software (16-17 April 2019) to test the usability of the final beta versions of the individual tools in the RAIF and LIQUEFACT software. The validation workshop used an enhanced version of the healthcare scenario used for the Rome workshop. Version 3 of the RAIF and version 2 of the LIQUEFACT software were developed following the workshop. All of the 
technical and business tools were integrated into a BAM planning framework following a half-day workshop (4th April 2019) using three different built asset scenarios (a primary health care scenario, a public building scenario, and a road transportation network scenario).

Detailed notes were taken at all workshops and meetings and where participants agreed the workshops and meetings were audio recorded. A more detailed description of the research process can be found in Morga et al. (2020). The research received ethical approval from Anglia Ruskin University, Science and Technology Research Ethics Panel.

\section{Results}

\subsection{Developing a conceptual built asset and community resilience model to EILD events}

A conceptual model (the RAIF) of the impact that EILD events have on built asset and community resilience was developed by combining the results of the literature review with Cutter et al. (2008) disaster resilience of place (DROP) model and Jones and Sharp (2007) performance-based BAM model (Morga et al. 2020). The RAIF adopted a two-phase approach similar to that developed by Taig (2012) to support an earthquake prone building policy review in New Zealand. Phase one assesses the impact that an EILD event has on functional performance of built assets. Phase two explores how mitigation options can be integrated into business continuity and resilience plans to reduce vulnerability or improve resilience. The RAIF can be applied at a single built asset/site level or to a portfolio of assets to assess the impact of an EILD event at the system level (e.g. healthcare system) and at a city/regional level to assess the overall vulnerability/resilience of their communities. This paper reports the developments of the RAIF at the individual built asset and site level.

The development of the RAIF for EILD events builds directly on the work of the CREW project (Hallett 2013). The CREW project examined the implications that extreme weather events (both current and as a consequence of future climate change) could have on the performance of public housing in London. In the CREW project Cutter et al. (2008) DROP model was combined with Jones and Sharp's (2007) performance-based BAM model to develop a risk framing tool for built asset managers to better understand their built assets current and future vulnerabilities and resilience to fluvial flooding and extreme heat waves. In developing the risk framing tool the CREW project developed a methodology for assessing the vulnerability and resilience of individual house units and identifying potential technical adaptation and mitigation options to either reduce vulnerability, improve resilience, or both (Hallett 2013). The CREW project also developed a methodology for combining the impact that an extreme weather event has on individual house units to the impact that it has at the portfolio level to obtain an overall assessment of the physical vulnerability and resilience of public housing providers housing stock (e.g. at the system level). In a subsequent project Jones (Jones et al. 2017) developed a methodology for integrating the adaptation and mitigation interventions identified in the CREW risk framing tool into the housing provider's disaster management and contingency planning and developed a BAM planning tool that integrated the housing provider's built assets physical vulnerability and resilience within its wider organisational capabilities to develop a prioritisation framework 
for identifying and programming cost-effective adaptation and mitigation options into the built asset life-cycle.

The LIQUEFACT project extended the approach detailed above to consider the impact that an EILD event would have on the vulnerability and resilience of built assets. Figure 4 (the final version of the RAIF) shows the results of the mapping exercise between Cutter et al. DROP (2008) model and Jones and Sharp's performance based BAM model (2007) represented as a 5-stage decision making framework.

\subsection{Validation of the RAIF}

The RAIF was tested through two workshops in Bologna and Ferrara. The RAIF was presented to a stakeholder workshop in Bologna and a technical workshop of LIQUEFACT researchers in Ferrara. A general discussion with participants (Bartolucci and Jones 2016) and a short exploratory questionnaire of approaches to modelling resilience (Morga et al. 2020) with the Bologna workshop participants confirmed the suitability of the general approach adopted by the RAIF. Detailed discussions with each LIQUEFACT research team at the Ferrara workshop confirmed the technical feasibility of the RAIF to assess built asset and community resilience to an EILD event and developed design guidance and data specifications for each of the tools/models (Bartolucci and Jones 2016). The process stages in the RAIF and the associated design requirements of the LIQUEFACT tools are summarised in Table 1 (Morga et al. 2020).

The first versions of the LIQUEFACT tools developed against the requirements identified in Table 1 were presented at a two-day LIQUEFACT technical workshop and one-day IEAG workshop. During the technical workshop each research team presented the theoretical basis to their tools which were critiqued by other LIQUEFACT researchers and suggestions of refinements to the theoretical base, or alternative approaches to the tool development, were discussed. The interrelationships between the LIQUEFACT tools (the ability

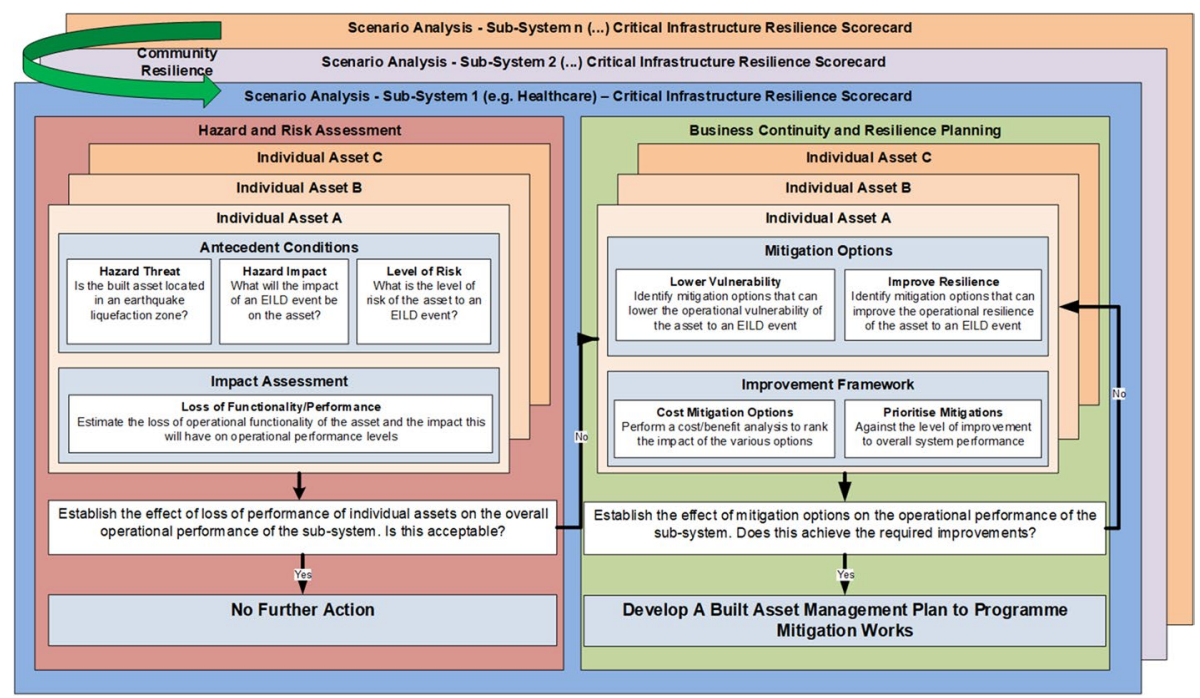

Fig. 4 The resilience assessment and improvement framework 
Table 1 RAIF stage and associated LIQUEFACT tools (summarised from Morga et al. 2020)

\begin{tabular}{|c|c|}
\hline RAIF stage & Practical tools \\
\hline $\begin{array}{l}\text { Antecedent } \\
\text { conditions }\end{array}$ & $\begin{array}{l}\text { Hazard threat: Assessment of the vulnerability of an asset(s) to an EILD event using mac- } \\
\text { rozonation/microzonation maps and/or site-specific ground investigations } \\
\text { Hazard impact: Assessment of the potential damage profile to the built asset using fragility } \\
\text { curves that combine soil profile, structure characteristics, seismic hazard and ground } \\
\text { motions to assess the probability of the hazard impact exceeding pre-set damage limit } \\
\text { states } \\
\text { Level of risk: Assessment of the damage state (slight, moderate extensive and complete } \\
\text { damage) and mean damage ratio of individual assets }\end{array}$ \\
\hline $\begin{array}{l}\text { Impact } \\
\text { assessment }\end{array}$ & $\begin{array}{l}\text { Loss of functionality/performance: Assessment of the impact that the each of the damage } \\
\text { states would have on the functional performance (service delivery, production output etc.) } \\
\text { of the built asset. This assessment will require expert judgement linking knowledge of the } \\
\text { built asset user with the organisation's business continuity and resilience plans. Summing } \\
\text { the loss of functional performance of built assets within the subsystem gives an overall } \\
\text { assessment of the loss of performance at the subsystem level. If this is acceptable then no } \\
\text { further action is taken. If this is unacceptable mitigation options are evaluated }\end{array}$ \\
\hline $\begin{array}{l}\text { Mitigation } \\
\text { options }\end{array}$ & $\begin{array}{l}\text { Lower vulnerability/improve resilience: Identify a range of mitigation options to reduce the } \\
\text { vulnerability/improve resilience of the built assets to the impacts of an EILD event. The } \\
\text { mitigation actions could be either technical (e.g. ground improvement mitigation actions) } \\
\text { or operational (e.g. service redesign) or a combination of both }\end{array}$ \\
\hline $\begin{array}{l}\text { Improvement } \\
\text { framework }\end{array}$ & $\begin{array}{l}\text { Cost Options: Perform a cost benefit analysis for each mitigation option. Cost benefit analy- } \\
\text { sis will need to consider both direct and indirect costs, discounted to current value, and be } \\
\text { detailed enough to support an options appraisal analysis between mitigation options } \\
\text { Prioritise mitigations: The capacity of organisations to fund mitigation options will need to } \\
\text { be established along with an assessment of the risks of delaying the mitigation interven- } \\
\text { tion until later in the built asset life-cycle }\end{array}$ \\
\hline $\begin{array}{l}\text { Built asset } \\
\text { manage- } \\
\text { ment plan }\end{array}$ & $\begin{array}{l}\text { Program mitigation works: Once mitigation priorities have been set detailed design solu- } \\
\text { tions need to be developed and mitigation works programmed into the built asset life- } \\
\text { cycle. Wherever possible mitigation works should be programmed to coincide with the } \\
\text { built assets maintenance and refurbishment cycles }\end{array}$ \\
\hline
\end{tabular}

to share or pass data between the tools) and their integration into the RAIF and LIQUEFACT software were presented to the IEAG. The workshops confirmed the suitability of the general approach adopted by the RAIF but suggested the need for a one-day workshop to test the robustness of the individual theories underpinning each tool and on their ability to work together in the way expected in the RAIF.

\subsection{Operationalising the RAIF: the Rome sprint test}

The RAIF was operationalised using a hypothetical healthcare scenario during a one-day workshop with the LIQUEFACT researchers in Rome. A brief description of the hypothetical primary health scenario is given in Fig. 5. The qualitative impacts that an earthquake event has on the functional performance of a hospital and in particular the relationships between physical damage to built assets and functional performance (from a socioeconomic perspective) was informed by the work of Cimellaro et al. (2010), Achour (2007) and Achour et al. (2011).

A summary analysis of the results from the workshop is given in Table 2. As this was a qualitative analysis to prove the concept, no quantitative values were assigned to 


\section{Brief summary of the hypothetical hospital scenario}

The built asset manager for a regional hospital wanted to use the RAIF, LIQUEFACT software and tools to assess the potential impact of an EILD event on the functioning of the hospital immediately following an EILD event. The hospital is spread across 4 sites in a small city. Each site contains a mix of building types, that are generally in a good state of repair. Where the impact of an EILD event suggest a major impact on the ability of a single building (or portfolio of buildings on a site or across sites) the built asset manager wants to identify a series of mitigation options, with associated costs and benefits, that can be further evaluated as part of the strategic built asset management planning process and disaster management/business continuity planning.

Fig. 5 Summary of the Hypothetical Hospital Scenario used to operationalise the RAIF (adapted from Morga et al. 2020)

any factors, variables or thresholds. A more detailed analysis of the workshop results can be found Morga et al. (2020).

Whilst the theoretical concepts underpinning the RAIF did not change as a result of the workshop, the operational assumptions did.

For Risk and Hazard Assessment a third level of site assessment was added to the RAIF to reflect the uncertainty associated with the macrozonation and microzonation maps and their ability to reflect the level of risk at the individual built asset/site level. Individual site level ground investigation guidance was added to provide a final screening of the susceptibility of a particular site to earthquake induced liquefaction. Developing a comprehensive range of fragility curves for different building types and ground conditions was not possible in the time constraints of the LIQUEFACT project. As such the LIQUEFACT project produced 'typical' fragility curves and developed a rapid risk assessment procedure that end-users could use to develop bespoke fragility curves to reflect different building construction typology and ground conditions. Linking loss of built asset functionality to typical damage states using fragility curves is difficult (as they do not consider the operational or business circumstances of individual buildings). As such, the loss of functionality would be interpreted locally by the end-user to reflect the operational and business circumstances of the building system, and this would best be done through the disaster management/business continuity planning and built asset management process. To support this assessment the RAIF would require a range of damage profiles and mean damage state.

For Business Continuity and Resilience Planning only ground improvement interventions that would reduce the likelihood of ground liquefaction following an earthquake event, and service design and delivery models which would form the basis of an a customised scorecard were developed in the LIQUEFACT project. The approach to cost-benefit analysis changed from a wide area (geographical) disaster management approach to a narrow built asset/site options appraisal approach that would support the evaluation and prioritisation of built asset level mitigation interventions through strategic built asset management. From a community resilience perspective the UNDRR Disaster Resilience Scorecard for Cities was identified as an appropriate tool and a customised version of the Scorecard was developed for the LIQUEFACT project (described in Jones et al. 2020). A more detailed discussion of all of the above is contained in Morga et al. (2020). The results from the workshop were integrated into the RAIF and the LIQUEFACT software flow diagram (Fig. 6). 
Table 2 Summary of the analysis of the results from the workshop (summarised from Morga et al. 2020)

\begin{tabular}{ll}
\hline Question & Response \\
\hline $\begin{array}{l}\text { How susceptible are the hospital's buildings to an } \\
\text { EILD event? }\end{array}$ & $\begin{array}{l}\text { Geo-locating your sites onto macrozonation/micro- } \\
\text { zonation maps will identify which of the sites are } \\
\text { susceptible to a 'most probable' or 'most severe' } \\
\text { earthquake scenario }\end{array}$
\end{tabular}

What is the level of susceptibility for the buildings on the susceptible sites?

What is the potential impact of an EILD on the built assets on the sites?

What is the potential level of damage to the buildings?

What does this level of damage mean to the ability of these buildings to function?

What can be done to reduce the disruption that an EILD would cause to the functionality of the buildings?

What is the cost of retrofitting ground mitigation interventions?

How can these mitigation interventions be implemented?
A detailed analysis of ground characterisation and earthquake hazard characteristics of the susceptible sites will allow a RAG (Red, Amber, Green) rating of the sites susceptibility

Combining the foundation/soil characteristics and the building typology on the highly susceptible sites will allow a risk RAG rating for each building

Fragility curves will allow the level of damage to be predicted for high risk (or any risk level chosen by the client) buildings. The damage level would be in the form of qualitative assessments of damage state and level of confidence (e.g. a high probability of experiencing a moderate level of damage)

The ability of the buildings to deliver their core service needs to be assessed on a building by building basis using the hospital's risk assessment, disaster management, and business continuity plans. This analysis would be expressed in terms of the loss of functionality over time. Loss of functionality would be informed by expert opinion of those responsible for the hospital's disaster management plans as part of a wider disaster risk assessment

A range of ground mitigation interventions could reduce the impact that an EILD would have on the buildings. Changes to healthcare service design and delivery models could reduce the impact that damage to buildings could have on functionality

Although costs are building and site specific indicative costs will identify a number of potential mitigation interventions that can reduce damage levels at an acceptable cost-benefit ratio level

Detailed site analysis and mitigation design will confirm the potential of each cost-effective ground mitigation intervention. The most effective ground mitigation interventions will be programmed into the hospital's built asset management plans. A service delivery scorecard will assess the potential of changes to service design and delivery models

\subsection{Validating the RAIF and LIQUEFACT software}

The RAIF and LIQUEFACT software were validated at a two-day workshop between researchers at ARU and NORSAR. The workshop examined how the software could be applied to support each stage of the RAIF and in particular how the RAIF and LIQUEFACT software could be integrated into a BAM planning tool. The workshop used an enhanced version of the healthcare scenario used in the Rome workshop. The enhanced 


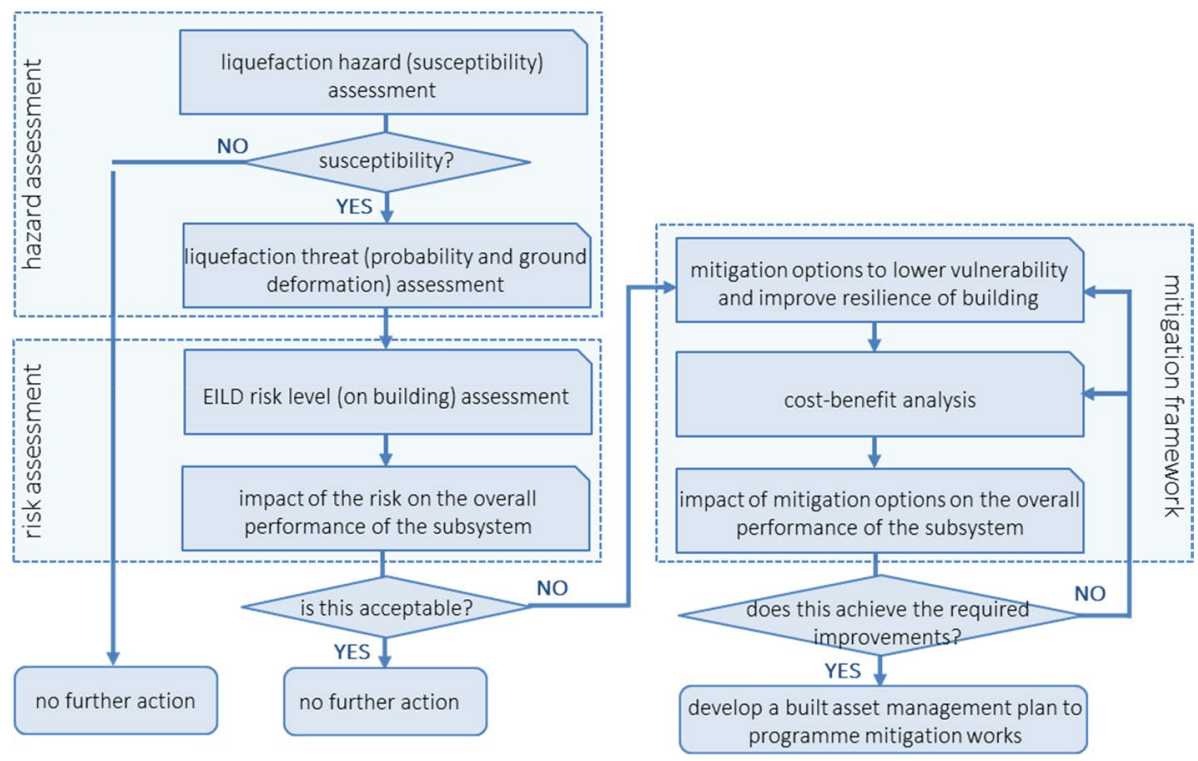

Fig. 6 The LIQUEFACT software flow diagram

version retained the same overall objectives as the Rome workshop (Table 2) but the evaluation of each stage of RAIF was considered in greater detail.

Through the LIQUEFACT software users can geo-locate their assets against the macrozonation and microzonation maps in the software and identify those assets/sites that are potentially susceptible to an EILD hazard (Fig. 7).

For potentially susceptible sites users can commission a detailed ground investigation (e.g. CPT data, SPT data or VS30 profile) and this data can be used by the software to customise the level of susceptibility to specific site conditions. Users can either use inbuilt earthquake scenarios or enter their own earthquake scenario data.

The LIQUEFACT software produces a number of measures for liquefaction potential (e.g. Liquefaction Potential Index, Liquefaction Severity Number, Equivalent Soil Profile and settlement) along with a qualitative assessment (very low to very high) of the liquefaction risk level for each location (Fig. 8).
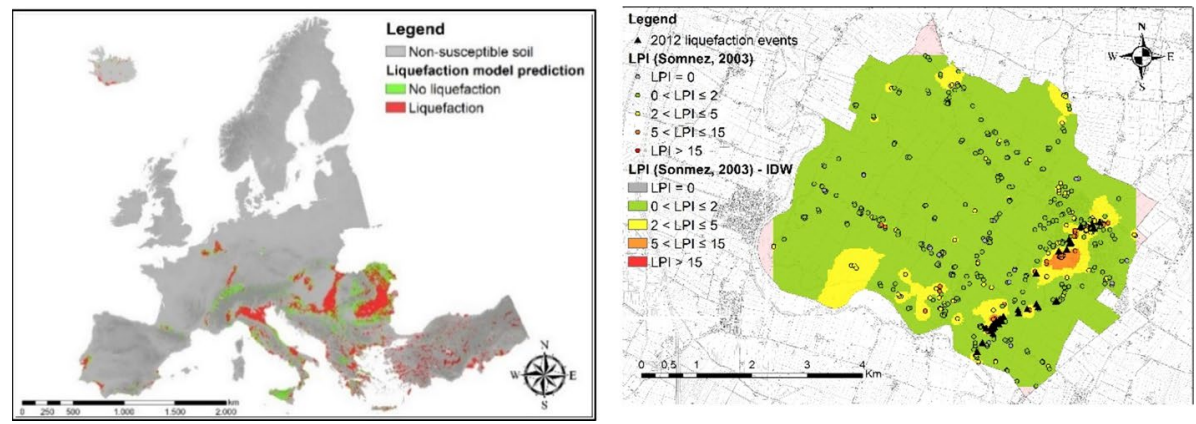

Fig. 7 Example of screen shots for EILD susceptibility 


\begin{tabular}{|c|c|c|c|c|c|c|c|c|c|c|c|c|c|c|}
\hline \multirow{2}{*}{\multicolumn{2}{|c|}{$\begin{array}{l}\text { Hazard Analysis Outbut } \\
\text { Seismic Ground Shaking }\end{array}$}} & \multicolumn{2}{|c|}{ Risk Analysis Output } & \multicolumn{11}{|c|}{ Mitigation Andysis Output } \\
\hline & & Ground $L$ & iquefaction & & & & & & & & & & & \\
\hline \multicolumn{2}{|c|}{ List (Profiles) } & $\cdot$ & & & & & & & & & & & & \\
\hline & \multicolumn{2}{|c|}{ Hazard Identification } & Latitude & Longitude & $\begin{array}{c}\text { PGA } \\
\text { (amplified) }\end{array}$ & $\begin{array}{c}\text { PGA } \\
\text { Assignment }\end{array}$ & LPI & Settlement $(\mathrm{cm})$ & LSN & LSN (ESP) & ESP & $\begin{array}{l}\text { Liquefaction Risk Level } \\
\text { (LPI-Based) }\end{array}$ & $\begin{array}{l}\text { Liquefaction Risk Level } \\
\text { (LSN-Based) }\end{array}$ & $\hat{\imath}$ \\
\hline 5 & \multicolumn{2}{|c|}{$185130 \mathrm{C} 002$} & 44.801200 & 11.406200 & 0.218684 & G063 & 6.3552 & 10.0003 & 20.8304 & 30.1025 & WMS & High & Moderate & \\
\hline 6 & \multicolumn{2}{|c|}{$185130 C 003$} & 44.801200 & 11.408000 & 0.218684 & G065 & 2.5023 & 4.8032 & 12.4415 & 32.7532 & WMS & Moderate & Moderate & \\
\hline 7 & \multicolumn{2}{|c|}{$185130 c 004$} & 44.803500 & 11.412900 & 0.139958 & G116 & 0.0000 & 1.3947 & 4.1115 & 0.0000 & $R X X$ & None & None & \\
\hline 8 & \multicolumn{2}{|c|}{$185130 C 006$} & 44.800600 & 11.414500 & 0.218684 & 6058 & 2.5024 & 4.7398 & 14.3978 & 47.3038 & WMS & Moderate & Moderate & \\
\hline 9 & \multicolumn{2}{|c|}{$185130 C 007$} & 44.805500 & 11.413800 & 0.139958 & G163 & 0.0000 & 1.2970 & 3.8116 & 0.0000 & $R X X$ & None & None & \\
\hline 10 & \multicolumn{2}{|c|}{$185130 \mathrm{CO008}$} & 44.805200 & 11.414500 & 0.139958 & G163 & 0.0000 & 0.4866 & 1.7536 & 0.0000 & $R X X$ & None & None & \\
\hline 11 & \multicolumn{2}{|c|}{$185130 C 009$} & 44.804600 & 11.411100 & 0.139958 & G144 & 0.0000 & 0.7770 & 1.2537 & 0.0000 & $\mathrm{RXX}$ & None & None & \\
\hline 12 & \multicolumn{2}{|c|}{$185130 C 010$} & 44.803500 & 11.410000 & 0.139958 & G113 & 0.0000 & 1.2833 & 2.4692 & 0.0000 & $R X X$ & None & None & \\
\hline 13 & \multicolumn{2}{|c|}{ 185130C011 } & 44.802000 & 11.414200 & 0.218684 & G088 & 7.7130 & 9.9757 & 22.2687 & 43.7311 & WMM & High & Moderate & \\
\hline 14 & \multicolumn{2}{|c|}{$185130 \mathrm{CO} 012$} & 44.806600 & 11.404800 & 0.218684 & G181 & 1.6611 & 2.4675 & 7.1477 & 34.0062 & WMM & 1 Low & Low & \\
\hline 15 & \multicolumn{2}{|c|}{$185130 \mathrm{C} 013$} & 44.807400 & 11.406800 & 0.218684 & G199 & 1.2112 & 2.8536 & 10.1765 & 49.5711 & WLS & Low & Moderate & s \\
\hline
\end{tabular}

Fig. 8 Example of liquefaction risk levels for a range of buildings

The risk level can be generated against a number of earthquake scenarios to allow users to build risk profiles that reflect their local attitudes towards risk. Those buildings requiring further investigation can be identified by considering the impact that the building's function has on the organisations critical success factors. For example, in the healthcare sector scenario, buildings that provide primary care services and are at a 'high' level of risk may be investigated further whilst 'high' level risk buildings providing back office support may not be. This assessment will be made with reference to the user organisation's risk assessment and disaster management/business continuity plans.

For those buildings identified for detailed investigation the user describes the building typology (e.g. construction material, structural system, number of stories, foundation system) and the LIQUEFACT software generates damage profiles (probability of slight damage, probability of moderate damage, probability of extensive damage, probability of complete collapse) and the mean damage ratio (referred to as the Mean Loss Ratio) for the building against each earthquake scenario. The LIQUEFACT software

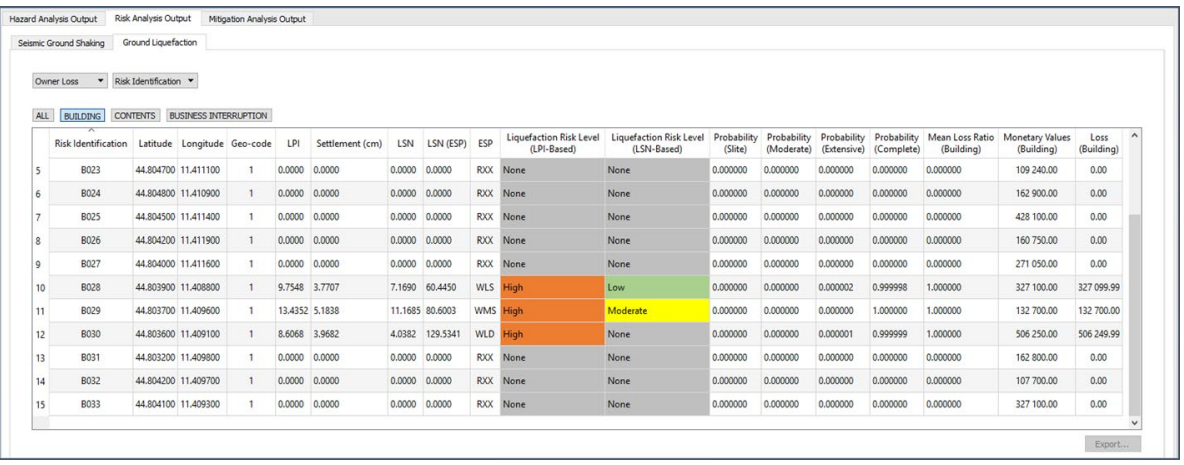

Fig. 9 Example of damage and losses associated with each building 
also estimates the expected annual loss (physical damage, contents damage, and business disruption) associated with the Mean Loss Ratio (Fig. 9) for each building.

Finally, the LIQUEFACT software suggests a range of possible cost-effective mitigation options based on the cost to implement a given ground improvement mitigation technology to each individual structure/infrastructure; the benefit (in terms of reduced loss) when applying the given mitigation technology; and cost-benefit ratio which is linked to the expected annual loss. This process is repeated for a range of mitigation options, which includes vertical and horizontal drains, deep dynamic compaction, vibro-compaction, blasting compaction, vibro replacement, induced partial saturation, compaction grouting, low pressure grouting, jet grouting, deep soil mixing (Flora et al. 2020). This process allows the user to prioritise potential mitigation options that can be further evaluated through direct discussions with specialist contractors prior to commissioning a full feasibility study of the mitigation intervention.

Following the validation workshop the BAM Planning tool (Table 3) was developed. The BAM planning tool provides a 10 step approach for built asset managers to assess the impact that an EILD event would have on their built assets and evaluate the potential of mitigation interventions to reduce the impact.

Finally, the applicability of the RAIF and BAM planning tool were tested in a half-day workshop in Turkey held with LIQUEFACT researchers against three different built asset scenarios (a primary health care scenario, a public building scenario, and a road transportation network scenario). The workshop confirmed the suitability of the BAM planning framework (and its associated tools) for assessing the potential of ground mitigations to improve the resilience of built assets to an EILD event.

\section{Discussion}

Improving resilience to EILD events is a complex task, requiring actions by both technical and non-technical stakeholders to understand the impacts that an EILD event has on the functionality of built environment systems and how any loss in functionality is managed to reduce its impact on the wider community. The RAIF and BAM tool described in this paper provide the conceptual framework and business support tool to allow engineers/built asset managers identify the potential impacts that an EILD could have on built assets and evaluate the potential of mitigation interventions to reduce this impact.

The development of the RAIF and BAM planning tool brought together a range of technical experts and end-user stakeholders in an iterative research process to develop, test and validate a conceptual model of built asset resilience to an EILD and to operationalise the model through a 10 step BAM planning tool. The conceptual model was based on a combination of Cutter et al. (2008) DROP model and Jones and Sharp's (2007) performance based BAM model; interpreted in the context of the built asset life-cycle.

Whilst the research methodology used in the LIQUEFACT project did not strictly follow an action research methodology, as there was no direct testing of the prototype by endusers against real world situations, it did follow action research principles: planning, implementation, reflection and review with internal and external stakeholders and international advisors (Fig. 3). Adopting such an approach allowed the LIQUEFACT research teams to develop theoretical solutions that addressed engineering science in the context of its practical application by both technical and non-technical stakeholders. In essence researchers were required to explicitly consider a 'so what' question at each stage of their research; 


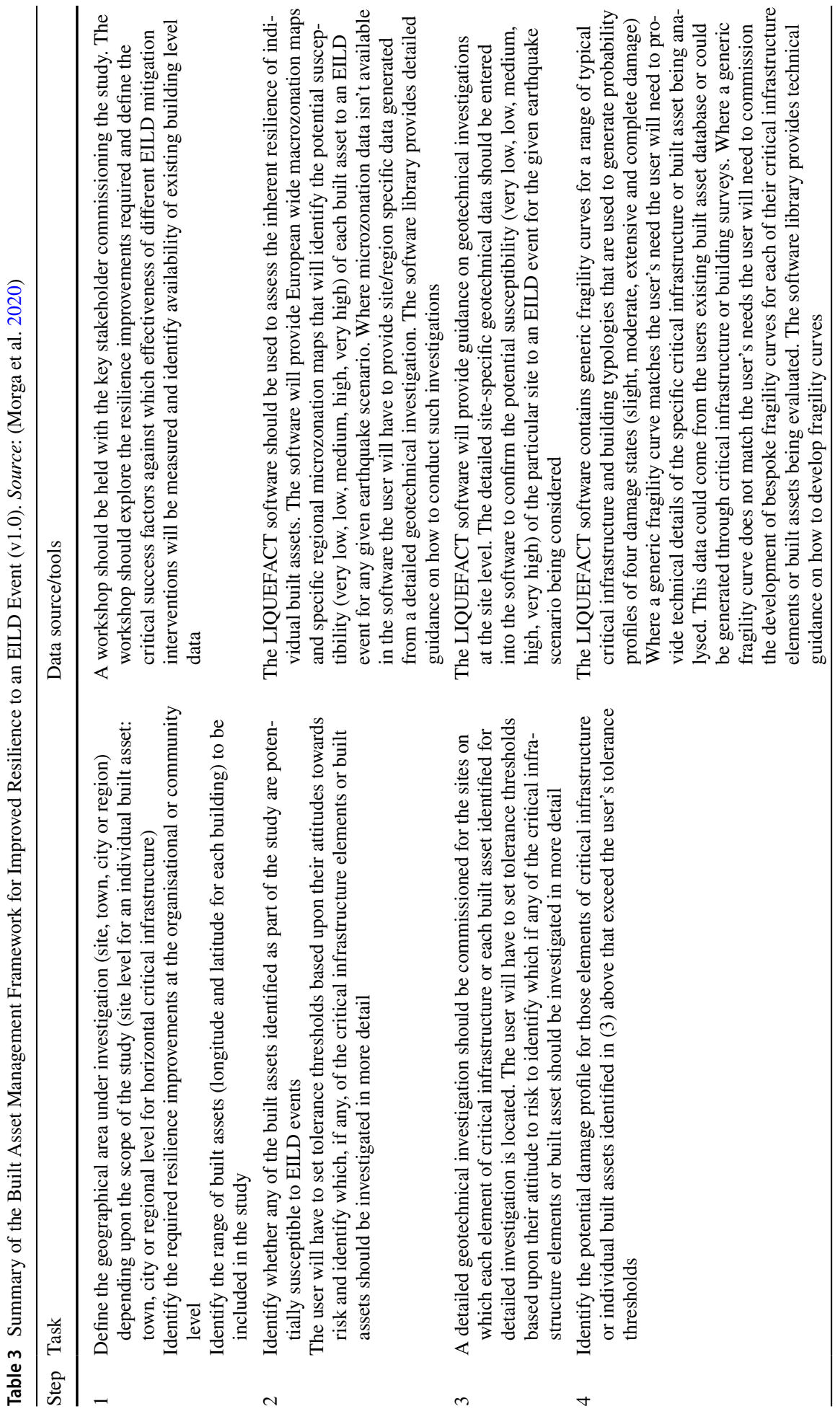




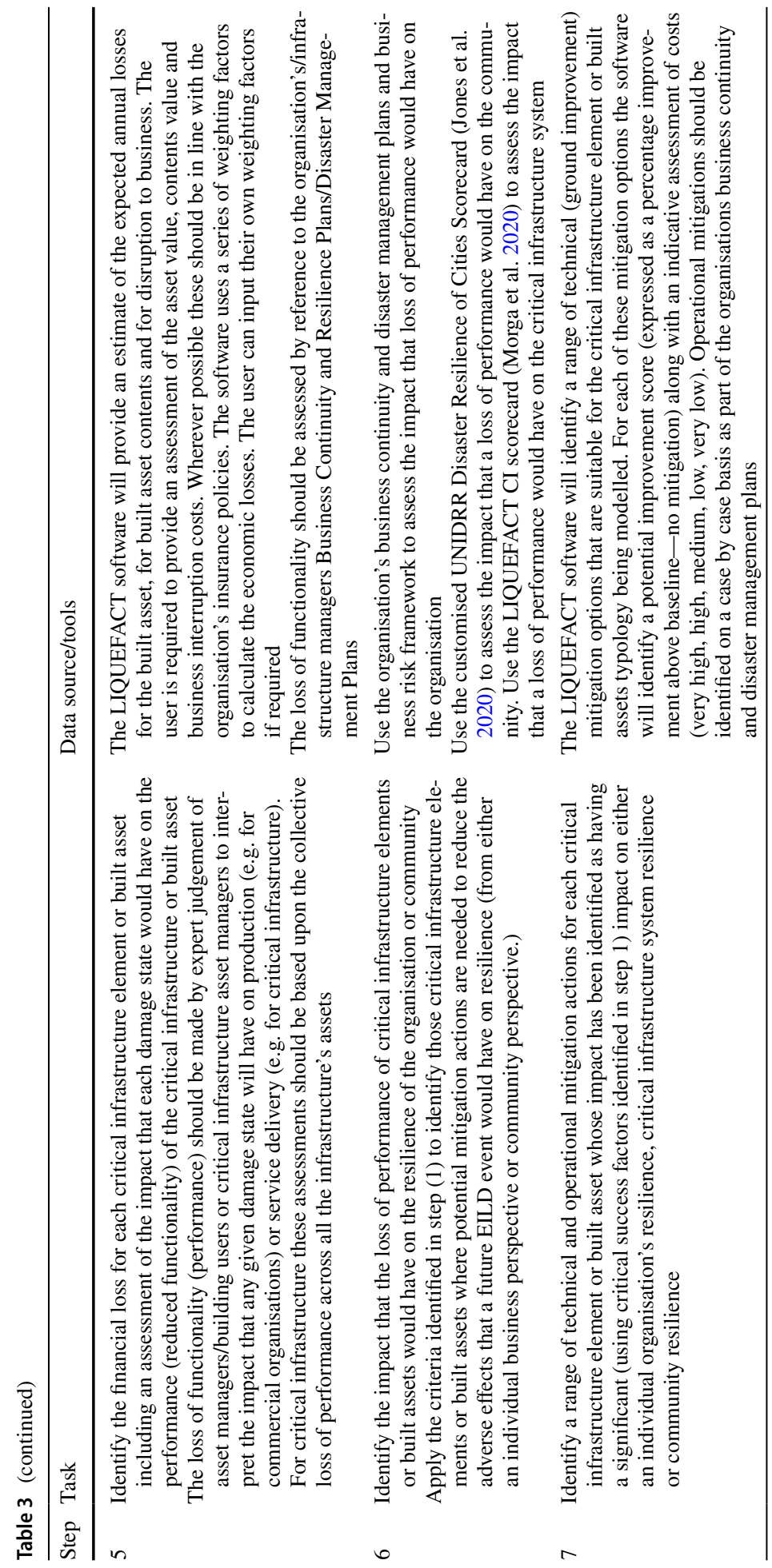




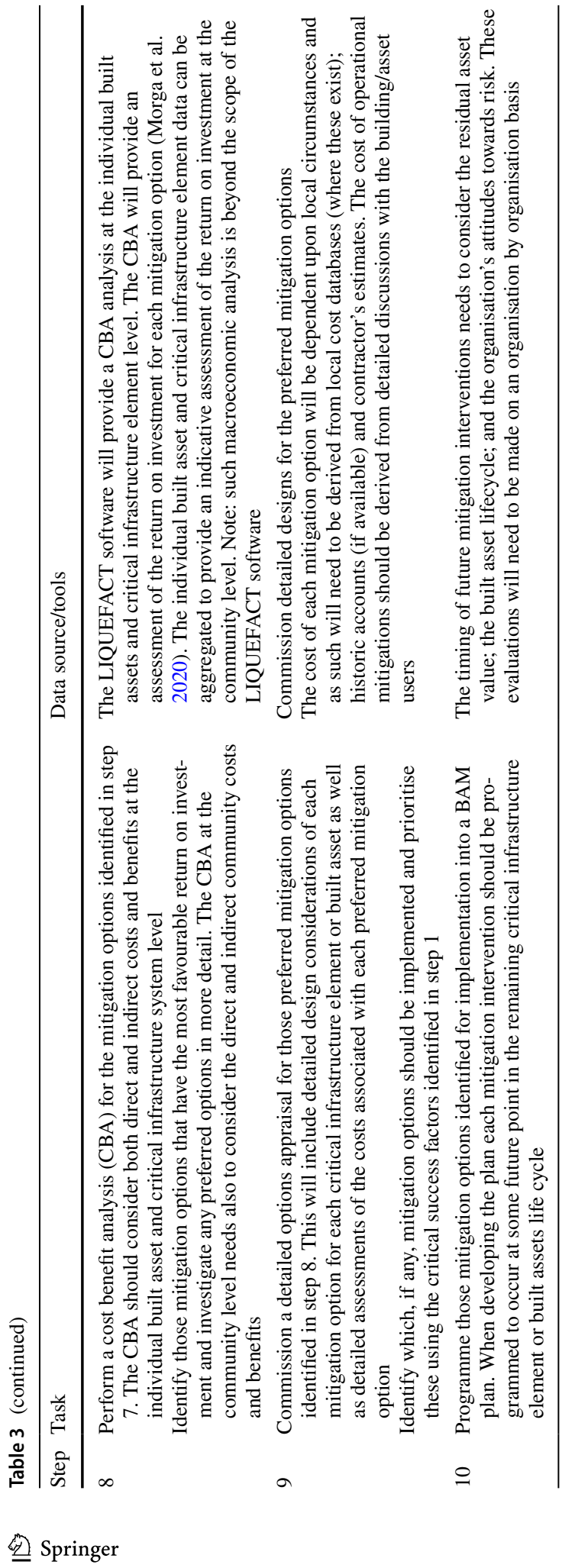


having to justify to the wider LIQUEFACT team, expert stakeholders and the IEAG not only the engineering/scientific significance of their work, but also the practical impact that their results would have. Whilst addressing the route to impact of research as an integral part of the research process did cause tensions between some members of the project team it ultimately produced a set of end-user tools that could be readily integrated into the LIQUEFACT software; which was a primary requirement of the LIQUEFACT project.

Studies that have examined the resilience of existing built assets to disaster events (Johnston et al. 2017; Melkunaite 2016; Taig 2012) have tended to develop explanatory or descriptive models that, whilst helping frame and understand the disaster risks, do not contain the business tools needed to justify the inclusion of mitigation interventions into BAM plans. Whilst the background theories used to support the development of the RAIF were well established in their own fields, they had not previously been combined to provide a longitudinal, holistic model of the resilience of existing built assets over their life cycle. The LIQUEFACT project successfully combined the different theories into a holistic framework for assessing the potential impact of an EILD event on existing built assets and identifying potential mitigations to improve the resilience of the built assets. The longitudinal model underpinning the development the RAIF and BAM planning tool also addressed the problems identified by several authors (Alwan and Gledson 2015; Ebinger and Madritsch 2012; Munir et al. 2019; Smyth et al. 2017; Too and Too 2010) of linking built asset performance to BAM planning. By adopting an iterative research methodology the individual LIQUEFACT tools were developed, tested and refined as the project progressed which resulted in a holistic toolbox that supported a pro-active, rather than reactive, approach to BAM decision making to improve built asset resilience to disaster events.

The testing of the RAIF and BAM planning tool against a range of hypothetical scenarios identified a number of issues that require further research before fully operational tools can be developed. Whilst the macrozonation/microzonation maps provide an initial screening tool for built asset managers to identify which of their built assets are potentially susceptible to an EILD event, the level of granularity of the maps is not sufficient to identify susceptibility at the individual site or built asset level. As such site based investigations will be needed and although the LIQUEFACT software provides guidelines on how to commission such studies their costs are likely to be high compared to the potential benefits that could accrue from reduced losses to EILD events. As such it is unlikely that detailed site based investigations will be performed unless the built assets located on the site have a critical impact on the overall resilience of the organisation or wider community. More research is needed to improve the granularity of the macrozonation/microzonation maps or reduce the cost of site based investigations.

Translating seismic activity and ground/building typology into functional damage states proved very difficult. The traditional approach of using fragility curves to predict the level of damage did not provide the level of detail required to allow the impact of an EILD on the functional performance of built assets (impact on primary services) to be assessed. From an operational perspective built assets functional performance is not only affected by the damage to structural elements, but also by damage to the non-structural elements (Achour 2007; Achour et al. 2011; Cimellaro et al. 2010). It became clear from the technical modelling undertaken that the very localised nature of EILD occurrence, combined with the relatively low levels of structural damage caused by EILD events, made it difficult for structural engineers to directly model the impact of an EILD event on non-structural elements; or present their data in a form that allowed built asset managers to quantify the impact of an EILD on the delivery of their primary services. As such the RAIF relies on the expert judgement of local built asset managers to interpret the impact that the damage states have 
on service delivery as part of their disaster risk management and business continuity planning. Going forward the authors suggest the need for fragility models for EILD events to be developed that reflect the 'functional service level' requirements of a built asset.

The RAIF assumes that the impact that EILD events have on the operational performance of the subsystem to which the individual built assets belong can be assessed by aggregating the impacts of each individual built asset. Whilst this assumption is valid from a technical perspective, it doesn't account for the wider complexity within the subsystem. For example, the overall resilience of a healthcare system is governed by the ability of the system to reorganise following a disaster event and a simple summation of impacts across the system does not model this phenomena. The LIQUEFACT project began the development of a multi-criteria (technical, operational, and organisation/managerial) critical infrastructure resilience assessment tool for EILD events (Morga et al. 2020) but further work is needed before this tool can be applied in a qualitative or hybrid (semi-quantitative) approach.

The LIQUEFACT project developed a number of EILD mitigation interventions (vertical drains, horizontal drains, partial ground saturation) and these, along with existing EILD mitigation interventions are incorporated in the LIQUEFACT software. In addition the LIQUEFACT software also provides a detailed cost-benefit tool to allow specific mitigation interventions to be assessed at both the individual built asset and portfolio level (Wanigarathna et al. 2018; Morga et al. 2020). The cost-benefit tool was derived from an options appraisal approach which assumed that the risks to the organisation's built assets were sufficiently high to warrant full investigation of potential mitigation interventions. As such, whilst the approach is consistent with that used for other (non-disaster related) built asset mitigation interventions, and with the localised nature of EILD events, it doesn't fully address the impact that the residual asset value (i.e. where the disaster occurs on the built asset life cycle) has on mitigation priority decision making. Further work is needed to introduce residual asset value into the cost-benefit model.

The BAM planning tool presented in this paper (Fig. 9) describes a management decision support tool for built asset managers to assess their built assets' vulnerability and resilience to an EILD event. However, given that the tool was developed from a previous version that assessed the impact of extreme weather on social housing (Hallett 2013) the authors believe that the principles behind its design can provide the basis for the development of similar business tools for other earthquake impacts and disaster events.

Finally, the RAIF assumes that the impact of an EILD event on overall community resilience can be assessed by combining the impact that an EILD event has on each subsystem. Whilst detailed discussion of this stage is beyond the scope of this paper the LIQUEFACT project developed a customised version of the UNDRR Disaster Resilience Scorecard for Cities (UNDRR 2017) which can be found in Jones et al. (2020) and Morga et al. (2020).

\section{Conclusions}

This paper describes the development of a RAIF and associated BAM planning framework to support both technical and non-technical end-user stakeholders identify the impact that a EILD event would have on the functional performance of their built assets and identify a range of physical and operational mitigation intervention options that could reduce this impact. The paper used a series of hypothetical scenarios to prove the concepts behind the RAIF and BAM framework but, due to lack of time, it was not 
possible to validate the RAIF of BAM framework against a real organisation. This work still needs to be done before firm conclusions about the validity of the RAIF and BAM framework can be drawn, or before the effectiveness of EILD mitigations to improve built asset resilience can be made.

This paper argued the need for a longitudinal, holistic view to be taken of disaster vulnerability and resilience, where hazard and risk assessment leads to specific actions to improve business continuity and resilience planning; suggesting that the integration of the DROP model (Cutter et al. 2008) with a performance based built asset management model (Jones and Sharp 2007) can provide such a view. Although the DROP model (ibid) was originally developed for assessing community resilience to disaster events the author's believe that it's application at an organisational level demonstrates the models wider applicability to understand the link between vulnerability and resilience for other location based disaster events; and demonstrates its ability to provide the theoretical basis to holistically address both engineering and socioecological resilience concepts.

The RAIF was operationalised through the development of a BAM framework to provide a business decision tool to support pro-active mitigation planning to lower built asset vulnerability and increase resilience to EILD events. Whilst developing the tool identified a number of conflicts between quantitative and qualitative approaches to disaster risk management it again reinforced the need for real-world solutions to adopt a holistic, systems view of resilience (Melkunaite 2016; Mieler et al. 2015) that combines both engineering and socioecological resilience concepts (Holling 2001). The challenge going forward is to develop multi-disciplinary models and tools that effectively combine quantitative and qualitative metrics into the disaster risk management and business continuity and resilience planning. This is an area of research that needs to be addressed if built asset resilience is to be improved.

The development of the RAIF and BAM framework adopted a interactive research methodology that sought to actively engage end-user stakeholders as full members of the research team; as opposed to research subjects to studied. Whilst this methodology at time caused tension between team members the authors believe that it provided a robust methodological framework that supported the delivery of an engineering prototype (the LIQUEFACT software and tools) that reflected the needs of end-users. Asking the 'so what' question (so what does this particular piece of research add to the RAIF, BAM framework or LIQUEFACT software or tools) challenged researchers to justify how their research activities supported real-world impact. The authors would recommend a similar approach to those researching multi-disciplinary real-world problems.

Finally, although the focus of the research presented in this paper is EILD events the authors believe that the approach described in the paper along with the generic BAM planning framework can provide the basis for developing similar solutions for other disaster events.

Acknowledgements The authors would like to acknowledge the advice and guidance they received from all of the LIQUEFACT researchers during the development of the RAIF and BAM planning framework.

Funding This project has received funding from the European Union's Horizon 2020 research and innovation programme under Grant Agreement No. 700748.

Availability of data and material Will be available online following publication. 


\section{Compliance with ethical standards}

Conflict of interest The authors declare that they have no conflict of interest.

Open Access This article is licensed under a Creative Commons Attribution 4.0 International License, which permits use, sharing, adaptation, distribution and reproduction in any medium or format, as long as you give appropriate credit to the original author(s) and the source, provide a link to the Creative Commons licence, and indicate if changes were made. The images or other third party material in this article are included in the article's Creative Commons licence, unless indicated otherwise in a credit line to the material. If material is not included in the article's Creative Commons licence and your intended use is not permitted by statutory regulation or exceeds the permitted use, you will need to obtain permission directly from the copyright holder. To view a copy of this licence, visit http://creativecommons.org/licenses/by/4.0/.

\section{References}

Achour N (2007) Estimation of malfunctioning of a healthcare facility in case of earthquake, PhD Thesis from the Graduate School of Natural Science and Technology, Kanazawa University, Kanazawa, Japan. Abstract available at https://doi.org/10.1108/ijdrbe.2011.43502caa.002

Achour N, Miyajima M, Kitaura M, Price A (2011) Earthquake induced structural and nonstructural damage in hospitals. Earthq Spectra 27(3):617-634

Ainuddin S, Routray JK (2012) Earthquake hazards and community resilience in Baluchistan. Nat Hazards 63:909-937. https://doi.org/10.1007/s11069-012-0201-x

Ali FM, Jones K (2013) Negotiating community resilience in the city in a time of political change and deficit reduction. Int J Disaster Resil Built Environ 4(1):9-22. https://doi.org/10.1108/175959013112989 73

Alwan Z, Gledson BJ (2015) Towards green building performance evaluation asset information modelling. Built Environ Proj Asset Manag 5(3):290-303. https://doi.org/10.1108/BEPAM-03-2014-0020

Bartolucci A, Jones K (2016) LIQUEFACT Deliverable 1.4 Detailed user requirements and research output protocols for the LIQEFACT Reference Guide. Available online at https://www.liquefact.eu/wp-conte nt/uploads/2018/12/D1.4-Detailed-user-requirements-and-research-output-protocols-for-the-LIQUE FACT-Reference-Guide.pdf. Accessed 4 Apr 2020

Bhattacharya S, Bolton M (2004), Buckling of piles during earthquake liquefaction. Proceedings of 13th world conference on earthquake engineering, vol 95. Vancouver, BC, Canada

Becker J, McBride S, Paton D (2013) Improving community resilience in the Hawke's Bay: a review of resilience research, and current public education, communication and resilience strategies, GNS Science Report 2013/38

Bird JF, Bommer JJ, Crowley H, Pinho R (2006) Modelling liquefaction-induced building damage in earthquake loss estimation. Soil Dyn Earthq Eng 26(1):15-30. https://doi.org/10.1016/j.soildyn.2005.10.002

Boon J, Cottrell A, King D, Stevenson JM (2012) Bronfenbrenner's bioecological theory for modelling community resilience to natural disasters. Nat Hazards 60:381-408. https://doi.org/10.1007/s1106 9-011-0021-4

Bray JD, Dashti S (2014) Liquefaction-induced building movements. Bull Earthq Eng 12:1129-1156. https ://doi.org/10.1007/s10518-014-9619-8

Bray JD, Macedo J (2017) 6th Ishihara lecture: simplified procedure for estimating liquefaction-induced building settlement. Soil Dyn Earthq Eng 102:215-231. https://doi.org/10.1016/j.soildyn.2017.08.026

Bruneau M, Chang SE, Eguchi RT, Lee GC, O'Rourke TD, Reinhorn AM, Shinozuka M, Tierney K, Wallace WA, von Winterfeldt D (2003) A framework to quantitatively assess and enhance the seismic resilience of communities. Earthq Spectra 19(4):733-752

Cavallo A (2014) Integrating disaster preparedness and resilience: a complex approach using a system of systems. Aust J Emerg Manag 29(3):46-51

Cimellaro GP (2016) Urban resilience for emergency response and recovery: fundamental concepts and applications. Springer, Berkeley

Cimellaro GP, Reinhorn AM, Bruneau M (2010) Seismic resilience of a hospital system. Struct Infrastruct Eng 6(1-2):127-144. https://doi.org/10.1080/15732470802663847

Cubrinovski M, Taylor D, Henderson A, Winkley J, Haskell BA, Bradley M, Hughes L, Wotherspoon J, Bray T, O'Rourke T (2014) Key factors in the liquefaction-induced damage to buildings and 
infrastructure in Christchurch: preliminary findings. In: Proceedings 2014 New Zealand society for earthquake engineering conference, The New Zealand Society for Earthquake Engineering Inc., Wellington, New Zealand

Cutter SL, Barnes L, Berry M, Burton C, Evans E, Tate E, Webb J (2008) A place-based model for understanding community resilience to natural disasters. Global Environ Change 18(4):598-606. https://doi.org/10.1016/j.gloenvcha.2008.07.013

Cutter SL, Burton CG, Emrich CT (2010) Disaster resilience indicators for benchmarking baseline conditions. J Homel Secur Emergency Manag, 7(1), article 51. Available online at: https://doi. org/7355.1732 Accessed Apr 42020

Davis S (2017) DRIVER D33.1-Community Resilience Model', DRIVER Project, available online at: https://driver-project.eu/wp-content/uploads/2017/11/Community-resilience-model.pdf. Accessed on Apr 42020

Ebinger M, Madritsch T (2012) A classification framework for facilities and real estate management; the built environment management model (BEM2). Facilities 30(5-6):185-198. https://doi. org/10.1108/02632771211208477

FEMA 454 (2006) Risk Management Series: Designing for Earthquakes-a manual for architects, FEMA available online at: https://www.fema.gov/media-library-data/20130726-1556-20490-5679/fema4 54_complete.pdf. Accessed 4 Apr 2020

FEMA E-74 (2012) Reducing the risks of nonstructural earthquake damage-a practical guide. FEMA. Available online at: https://www.fema.gov/media-library-data/1398197749343-db3ae43ef771e63 9c16636a48209926e/FEMA_E-74_Reducing_the_Risks_of_Nonstructural_Earthquake_Damag e.pdf. Accessed on 4 Apr 2020

Filiatrault A, Sullivan T (2014) Performance-based seismic design of nonstructural building components: the next frontier of earthquake engineering. Earthq Eng Eng Vib 13:17-46

Finch E (1998) A sea-change in facilities management. In: Alexander K (ed) Facilities management theory and practice. E \& FN Spon, London, pp 42-56

Fioravante V, Giretti D, Abate G, Aversa S, Boldini D, Capilleri PP, Cavallaro A, Chamlagain D, Crespellani T, Dezi F, Facciorusso J, Ghinelli A, Grasso S, Lanzo G, Madiai C, Massimino MR, Maugeri M, Pagliaroli A, Rainieri C, Tropeano G, Santucci De Magistris F, Sica S, Silvestri F, Vannucchi G (2013). Earthquake geotechnical engineering aspects: the 2012 emilia romagna earthquake (Italy). In: 7th International Conference on Case Histories in Geotechnical Engineering, Chicago U.S.A. paper EQ-5

Flora A, Bilotta E, Fasano G, Mele L, Nappa V, Chiaradonna A, Lirer S (2020) Liquefaction mitigation techniques guidelines, LIQUEFACT Deliverable 4.5, Available at https://www.liquefact.eu/wpcontent/uploads/2020/03/D4.5_bis.pdf. Accessed on 4 Oct 2020

Gallopin GC (2006) Linkages between vulnerability, resilience and adaptive capacity. Global Environ Change 16:293-303. https://doi.org/10.1016/j.gloenvcha.2006.02.004

Gibson CA, Tarrant M (2010) A conceptual models approach to organisational resilience. Aust J Emerg Manag 25(2):6

Hallett S (Editor) (2013) Community Resilience to Extreme Weather-the CREW Project: Final Report. 110pp.Available online at: https://arcc.ouce.ox.ac.uk/wp-content/pdfs/CREW_Final_Report.pdf Accessed on 16/03/2020. Accessed on 4 Apr 2020

Holling CS (1973) Resilience and stability of ecological systems. Annu Rev Ecol Syst 4(1):1-23

Holling CS (1996) Engineering resilience versus ecological resilience, engineering within ecological constraints, National Academy of engineering, ISBN: 0-309-59647-5. pp 31-44 Available online at: https://www.environmentalmanager.org/wp-content/uploads/2008/03/holling-eng-vs-eco-resil ience.pdf Accessed on 4 Apr 2020

Holling CS (2001) Understanding the complexity of economic, ecological, and social systems. Ecosystems 4:390-405. https://doi.org/10.1007/s10021-001-0101-5

Johnston D, Becker J, Cousins J (2017) Chapter 3 lifelines and urban resilience. In: Paton D, Johnston D (eds) Disaster resilience: an integrated approach. Charles C Thomas Publisher, Springfield

Jones K (2002) Best Value in Construction. In: Kelly J (ed) Chapter 15, sustainable building maintenance: challenge for construction professionals. Blackwell Science, New York

Jones KG (2012) Preparing for extreme weather events: a risk assessment approach. In: Booth C, Hammond F, Lamond J, Proverbs D (eds) Solutions to climate change challenges in the built environment. Wiley-Blackwell, New Jersey

Jones K, Sharp M (2007) A new performance-based process model for built asset maintenance. Facilities 25(13/14):525-535

Jones KG, Brydson H, Ali F, Cooper J (2013) Assessing vulnerability, resilience and adaptive capacity of a UK Social Landlord. Int J Disaster Resil Built Environ 4(3):287-296 
Jones K, Desai A, Brosnan N, Cooper J, Ali F (2017) Built asset management climate change adaptation model. Int J Disaster Resil Built Environ. https://doi.org/10.1108/IJDRBE-07-2016-0032/full/html

Jones K, Pascale F, Wanigarathna N, Morga M, Sargin S (2020) Critical evaluation of the customization process of the UNDRR disaster resilience scorecard for cities to earthquake-induced Soil liquefaction disasters events. Bull Earthq Eng (accepted)

Kramer SL (2014) Geotechnical earthquake engineering. Pearson, New York

Lundgren L, Jonsson A (2012) Assessment of social vulnerability a literature reive of vulnerability related to climate change and natural hazards, CSPP Briefing no 9, available online at: https://www.diva-porta 1.org/smash/get/diva2:552075/FULLTEXT01.pdf. Accessed on 4 Apr 2020

Manyena SB (2006) The concept of resilience revisited. Disasters. https://doi.org/10.111 1/j.0361-3666.2006.00331.x

Masi A, Santarsiero G, Nigro D (2013) Cyclic tests on external RC beam-column joints: role of seismic design level and axial load value on the ultimate capacity. J Earthq Eng 17(1):110-136. https://doi. org/10.1080/13632469.2012.707345

Matyas D, Pelling M (2012) Disaster vulnerability and resilience: theory, modelling and perspective. Government Office of Science, Foresight project 'Reducing Risks of Future Disasters: Priorities for Decision Makers'. Available online at: https://assets.publishing.service.gov.uk/government/uploads/system/ uploads/attachment_data/file/287456/12-1298-disaster-vulnerability-resilience-theory.pdf Accessed on 4 Apr 2020

Melkunaite L (Editor) (2016) Improved Risk Evaluation and implementation of resilience concepts to critical infrastructure-International survey, deliverable D1 .1, improve our project. available online at: https ://improverproject.eu/2016/06/23/deliverable-1-1-international-survey. Accessed on 4 Apr 2020

Mieler M, Stojadinovic B, Budnitz R, Comerio M, Mahin S (2015) A framework linking community-resilience goals to specific performance targets for the built environment. Earthq Spectra 31(3):1267-1283

Morga, M, Pascale F, Wanigarathna N, Majeed Z, Meslem A, and Jones K (2020) Whole life built asset management modelling framework: integrating mitigation to earthquake induced liquefaction disaster events into strategic built asset management, LIQUEFACT Deliverable 5.4, Available online at: https ://www.liquefact.eu/wp-content/uploads/2020/03/D5.4_bis.pdf. Accessed on Apr 42020

Munir M, Kivinemi A, Jones SW (2019) Business value of integrated BIM-built asset management. Eng constr archit manag. https://doi.org/10.1108/ECAM-03-2018-0105

Ostadtaghizadeh A, Ardalan A, Paton D, Jabbari H, Khankeh HR (2015) Community Disaster Resilience: a Systemeatic Review of Assessment Models and Tools. PLOS Currents Disasters. https://doi. org/10.1371/currents.dis.f224ef8efbdfcf1d508dd0de4d8210ed

Paton D (2007) Measuring and monitoring resilience in Auckland, GNS Science Report 2007/18

Paton D, Mamula-Seadon L, Selway KL (2013) Community resilience in Christchurch: adaptive responses and capabilities during earthquake recovery, GNS Science Report 2013/37

Paton D, Johnston D (2017) Disaster Resilience: an integrated approach, 2nd edn. Charles C Thomas Publisher, Springfield

Perrone D, Calvi P, Nascimbene R, Fischer E, Magliulo G (2019) Seismic performance of non-structural elements during the 2016 Central Italy earthquake. Bull Earthq Eng 17:5655-5677. https://doi. org/10.1007/s10518-018-0361-5

Pescaroli G, Alexander D (2016) Critical infrastructure, panarchies and the vulnerability paths of cascading disasters. Nat Hazards 82:175-192. https://doi.org/10.1007/s11069-016-2186-3

Prior T (2015) Measuring critical infrastructure resilience: possible indicators. Risk and Resilience Research Group Center for Security Studies, ETH Zürich

Prior T, Hagmann J (2012) Ski focus report 8-measuring resilience: benefits and limitations of resilience indices. Centre for Security Studies, ETH Zurich

Puḳītea I, Geipeleb I (2017) Different approaches to building management and maintenance meaning explanation. Procedia Eng 172:905-912

The Rockefeller Foundation (2015) City Resilience Index, Dec 2015, ARUP

Sharifi A (2016) A critical review of selected tools for assessing community resilience. Ecol Indic 69:629_ 647. https://doi.org/10.1016/j.ecolind.2016.05.023

Smyth H, Aaron A, Kusuma I (2017) Integrated solutions for total asset management through "RIVANS." Built Environ Proj Asset Manag 7(1):5-18. https://doi.org/10.1108/BEPAM-07-2015-0034

Taig T (2012) A risk framework for earthquake prone building policy. TTAC Report ref n132, New Zealand Ministry of Business, Innovation and Employment. Available online at: https://www.mbie.govt. nz/dmsdocument/76-risk-framework-for-earthquake-prone-building-policy-report-pdf Accessed 4 Apr 2020

Tierney K, Bruneau M. (2007) Conceptualizing and measuring resilience: A key to disaster loss reduction. TR News 250, May-June 2007 
Tiernan A, Drennan L, Nalau J, Onyango E, Morrissey L, Mackay B (2019) A review of themes in disaster resilience literature and international practice since 2012. Policy Des Pract 2(1):53-74. https://doi. org/10.1080/25741292.2018.1507240

Too E, Too L (2010) Strategic infrastructure asset management; a conceptual framework to identify capabilities. J Corp Real Estate 12(3):196-208. https://doi.org/10.1108/146300011011074795

UNDRR (2017) UNISDR, Terminology on Disaster Risk Reduction (2017) Available at: www.unisdr.org/ we/inform/terminology

UNISDR (2017) Disaster Resilience Scorecard for Cities', UNDRR, available online at: https://www.unisd r.org/campaign/resilientcities/assets/toolkit/Scorecard/UNDRR_Disaster\%20resilience\%20\%20sco recard\%20for\%20cities_Detailed_English.pdf. Accessed on 4 Apr 2020

UNDRR (2020) Disaster resilience scorecard for industrial and commercial buildings, available online at https://www.undrr.org/news/push-more-disaster-resilient-buildings-kicks-new-scorecard. Accessed on 4 Apr 2020

Van Ballegooy S, Malan P, Lacrosse V, Jacka ME, Cubrinovski M, Bray JD, O'Rourke TD, Crawford SA, Cowan H (2014) Assessment of liquefaction-induced land damage for residential Christchurch. Earthq Spectra 30(1):31-55

Warren CMJ (2010) The facilities manager preparing for climate change -related disaster. Facilities 28(11/12):502-513

Wang Y, Wang N, Lin P, Ellingwood B, Mahmoud H, Maloney T (2018) De-aggregation of community resilience goals to obtain minimum performance objectives for buildings under tornado hazards. Struct Saf 70:82-92

Wanigarathna N, Yarovaya L, Pascale F, Morga M, Jones K, (2018) Community resilience and cost/benefit modelling: Socio-technical-economic impact on stakeholder and wider community. LIQUEFACT Deliverable 5.3, Available online at: https://zenodo.org/record/1887957\#.XohtDG5Fy8g Accessed on 4 Apr 2020

Wood A, Noy I, Parker M (2016) The Canterbury rebuild five years on from the Christchurch earthquake. Bulletin 19(3). Reserve Bank of NZ. Available online at: https://www.rbnz.govt.nz/-/media/Reser veBank/Files/Publications/Bulletins/2016/2016feb79-3.pdf Accessed on 4 Apr 2020

Zheng W and Luna R (2006) Liquefaction effects on lateral pile behavior for bridges. In: Proceedings of the GeoShanghai Conference ASCE Geo-Institute, American Society of Civil Engineers (ASCE), Jan 2006. Available at https://doi.org/https://doi.org/10.1061/40865(197)34

Publisher's Note Springer Nature remains neutral with regard to jurisdictional claims in published maps and institutional affiliations. 